University of Nebraska - Lincoln

DigitalCommons@University of Nebraska - Lincoln

Si-Hwang Liou Publications

Research Papers in Physics and Astronomy

February 1988

\title{
Granular metal films as recording media
}

Sy_Hwang Liou

University of Nebraska-Lincoln, sliou@unl.edu

C.L. Chien

The Johns Hopkins University, Baltimore, Maryland

Follow this and additional works at: https://digitalcommons.unl.edu/physicsliou

Part of the Physics Commons

Liou, Sy_Hwang and Chien, C.L., "Granular metal films as recording media" (1988). Si-Hwang Liou Publications. 21.

https://digitalcommons.unl.edu/physicsliou/21

This Article is brought to you for free and open access by the Research Papers in Physics and Astronomy at DigitalCommons@University of Nebraska - Lincoln. It has been accepted for inclusion in Si-Hwang Liou Publications by an authorized administrator of DigitalCommons@University of Nebraska - Lincoln. 


\title{
Granular metal films as recording media
}

\author{
S. H. Liou a) and C. L. Chien \\ Department of Physics and Astronomy, The Johns Hopkins University, Baltimore, Maryland 21218
}

(Received 22 October $198 \%$; accepted for publication 4 December 1987)

\begin{abstract}
High-Gensity recording media require materials with a high magnetization and high coercivity as well as chemical stability, wear, and corrosion resistance. We explore the potential of granular metal fims for recording media. Fims of Fe granules about $150 \mathrm{~A}$ in size embedded in an amorphous $\mathrm{SiO}_{2}$ matrix exhibit coercivities as high as 3 kOe at low temperatures and 1.1 $\mathrm{kOe}$ at room temperature, and magnetizations of about $150 \mathrm{emu} / \mathrm{g}$. The methods with which these materials are fabricated, the essential microstructure characterization, and magnetic measurements are described.
\end{abstract}

Today, vast amounts of audio, video, and digital information are stored in magnetic tapes and disks. The demand for high-density recording media with superior magnetic characteristics is ever increasing. 'Suitable media for technological applications must also be chemically stable and wear resistant. Magnetic granular solids ${ }^{2}$ (e.g., Fe-SiO ${ }_{2}$ ), in which ultranne magnetic particles (with sizes $20-300 \mathrm{~A}$ ) are embedded in an insulating matrix, ofer atcractive features as recording media. First of all, the superior magnetic properties of the granular solids are microstructure controlled and can be tailored through process conditions. The insulating matrix (c.g., $\mathrm{SiO}_{2}, \mathrm{Al}_{2} \mathrm{O}_{3}$ ) greatly enhances the chemical stability of the magnetic particles, and the wear and corrosion resistance of the media. urthermore, since vapor deposition is the most effective method of making granular metal films, the fabrication, dispersion, and protection of the ultrafine granules, as well as coating onto desired surfaces suitable for device applications, are achieved in a single process.

In granular metal films, the microstructure is crucial to the unusual magnetic properties. The size and shape of the metal granules, their connectivity, and the associated percolation behavior are of primary importance. We have recently found in granular $\mathrm{Fe}-\mathrm{SiO}_{2}$ that when the metal volume fraction $(p)$ is near the percolation threshold $\left(p_{c}\right)$, greatiy enhanced magnetic properties are realized. ${ }^{3}$ s shown in Fig. 1, the coercivity $\left(H_{c}\right)$ at low temperatures was found to be as high as 25000 , two order of magnitude higher than that of bulk Fe. However, these sampies have been deposited onto room-temperature substrates, where the metal granales are relatively small ( $\leqslant 70 \AA$ ). Consequently, $H_{c}$ at room temperature is much reduced, primarily because of superparamagnetic relaxation. Fortunately, the magnetic properties can be further improved by altering the process conditions, particularly the substrate temperature.

In this work we demonstrate $F e$ granular inlms fabricated at different conditions with room-temperature coercivicy as high as 1125 Oe. Equaliy important, a magnetization of $150 \mathrm{emu} / \mathrm{g}$ (which is about twice of those of $\gamma-\mathrm{Fe}_{2} \mathrm{O}_{3}$ and $\mathrm{Co} \cdot \mathrm{Cr}$ ) has also been achieved. ${ }^{4,5}$ These characteristics compare very favorably with many existing media for magnetic recording. The relationship between these superior

\footnotetext{
a'Present adoress: A T\&T Bell Laboratories, Murray Hill, NJ 07974.
}

magnetic properties and microstructure will also be discussed.

The granular $\mathrm{Fe}-\left(\mathrm{SiO}_{2}\right)$ fims have been prepared by a high-rate if magnetron sputtering device with the use of composite targets of Fe and $\mathrm{SiO}_{2}$. All samples, except those for transmission electron microscopy (TEM), are about 2-5 $\mathrm{km}$ in thickness, deposited onto various substrates (glass, mica, Kapton, metals, alumina, etc.) suitable for specific measurements. Very good adhesion to Kapton, glass, and metal substrates has been noted. Sputter deposition has been made with substrates at various temperatures (77-875 K) in order to alter the morphology of the films. The microstrueture and composition of the samples have been characterized by TEM, electron, and $\mathrm{x}$-ray diffactions, atomic absorption, and ${ }^{57}$ Fe Mössbauer spectroscopy. The magnetic properties have been measured by a SQUDD magnetometer with a feld range of $0-50 \mathrm{kOe}$ and temperature range of $2-400 \mathrm{~K}$.

The composition of $\mathrm{Fe}_{75}\left(\mathrm{SiO}_{2}\right)_{25}$ with $p=0.42$ was chosen because a maximum in $H_{c}$ was achieved, as shown in Fig. 1. A number of process conditions, such as sputtering gas pressure, deposition rate, and substrate temperature, were varied in order to fabricate samples with different microstructure, particularly larger granuhe size. This is moti-

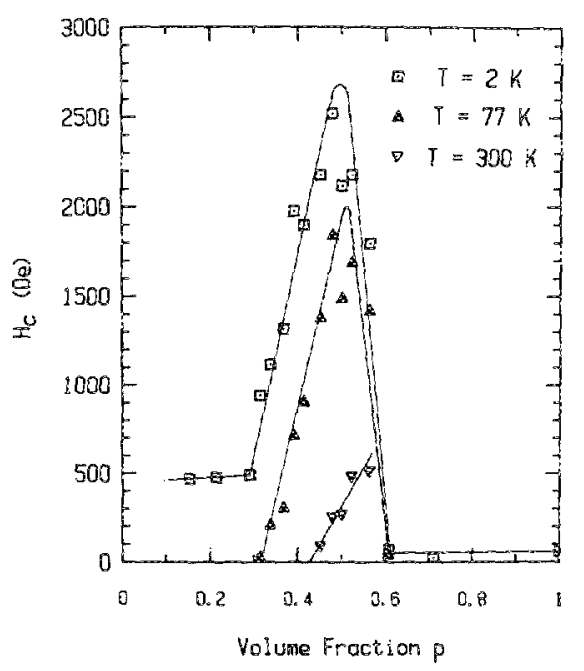

FIG. 1. Magnetic coercivities ( $T=2,77$, and $300 \mathrm{~K}$ ) of granular $\mathrm{Fe}_{-3 i O_{2}}$ films deposited onto room-temperature substrates as a function of Fe volume fraction ( $R$ of. 3 ). 


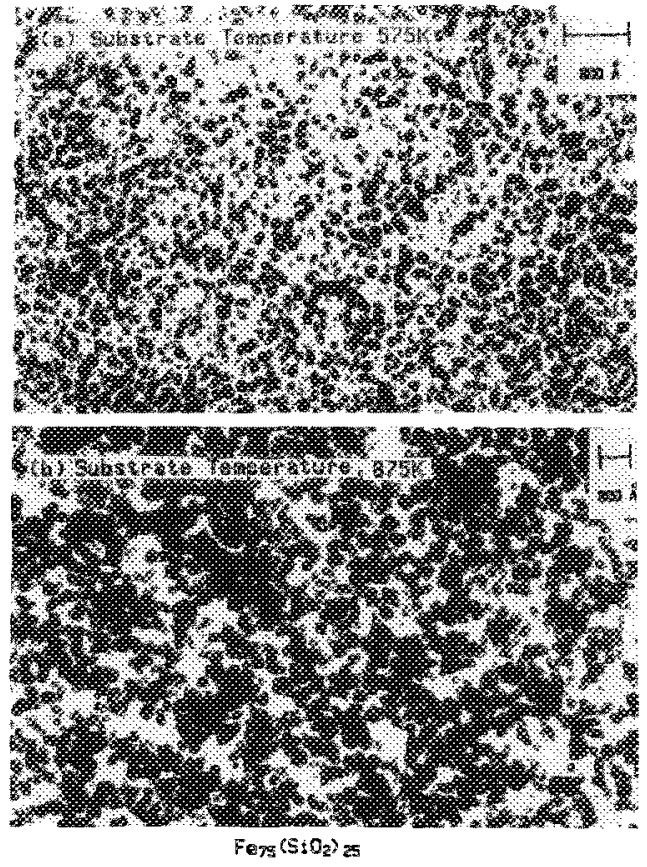

FIG. 2. TEM micrographs of $\mathrm{Fe}_{75}\left(\mathrm{SiO}_{2}\right)_{25}, p=0.42$, about 500 A thick, sputtered at substrate temperatures of $(a) 575 \mathrm{~K}$ and (b) $875 \mathrm{~K}$.

vated by the fact that the superparamagnetic relaxation rate depends sensitively on the particle size through the factor $\exp \left(K V / k_{Z} T\right)$, where $K$ is the magnetic anisotropy energy per volume and $V$ is the particle volume. ${ }^{6}$ Even a modest increase of $V$ (e.g., a factor of 2 ) should drastically alter the temperature dependence of the magnetic properties. Of the above-mentioned process conditions, substrate temperature has the most pronounced efect.

The granular nature of the $\mathrm{Fe}-\mathrm{SiO}_{2}$ samples with $p=0.42$ deposited onto substrates at substrate temperatures $\left(T_{s}\right)$ between 77 and $875 \mathrm{~K}$ is revealed by $\mathrm{TEM}$. For samples deposited between 77 and $400 \mathrm{~K}$, the granules are about $40 \mathrm{~A}$ and do not vary significantly in size. As shown in Fig. 2(a), the sample deposited at $T_{s}=575 \mathrm{~K}$ contains larger granuies of about $60 \AA$. The size of the granules can be greatly increased with higher $T_{s}$. As shown in Fig. $2(b)$, in the films deposited at $T_{s}=875 \mathrm{~K}$ the granule size is about $160 \AA$. Above $400 \mathrm{~K}$, the size of the gramules increases by about 25 $\AA$ per $100 \mathrm{~K}$. The $\mathrm{x}$-ray difraction pattern of a film deposited at $77.6 \mathrm{~K}$ is shown in Fig. 3. The pattern can be consistently indexed to the structure of bce $F e$ with a broad background contribution from amorphous $\mathrm{SiO}_{2}$. However, we note that the (110) peak at $45^{\circ}$ is slightly asymmetrical. The possibility of other phases of $\mathrm{Fe}$ is being investigated. We have also used ${ }^{57} \mathrm{Fe}$ Mössbauer spectroseopy to probe microscopically the Fe-containing portions of the samples. The spectra exhibit essentially the same hypertine field as that of $\alpha-F e$, although the linewidths are noticeably broader, as axpected from the small granules. There are no observable anounts of Fe oxides, which would generally exhibit much larger hyperfine fields. These analyses indicate that the granules are primarily pure $F e$.

From the value of $155 \mathrm{emu} / \mathrm{g}$ of total sample material for the saturation magnetization, measured at $6 \mathrm{~K}$, one ob-
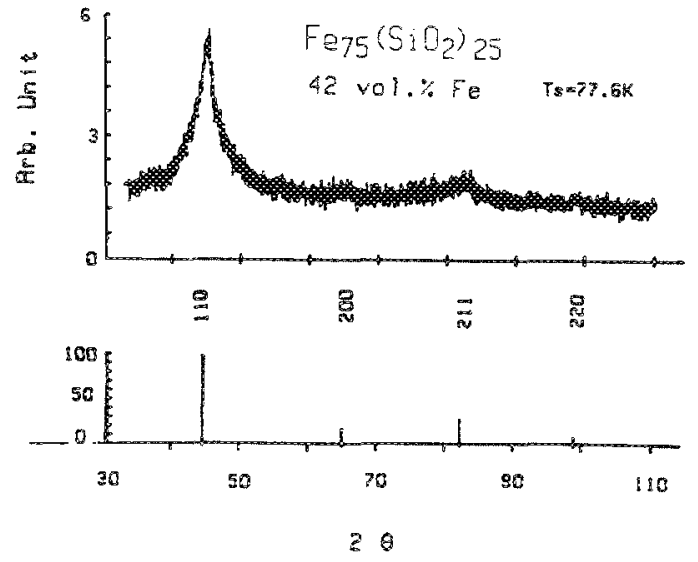

FIG. 3. X-ray diffraction pattern of $\mathrm{Fe}_{75}\left(\mathrm{SiO}_{2}\right)_{25}, p \ldots 0.42$, deposited at $T$, $=77.6 \mathrm{~K}$. The expected pattern for buk $\alpha-F e$ is also shown.

tains a value of 210 emu/g of Fe, which is within $5 \%$ of the value for pure $\mathrm{Fe}$. The magnetic moment per Fe is therefore about $2 \mu_{B}$. There is no evidence of enhancement or diminution of the Fe moment.

By increasing the granule size, as facilitated by higher $T_{s}$, the coersivity is dramatically affected in both magnitude and temperature dependence. As shown in Fig. 4 (a), $H_{c}$ at 6 $K$ increases from $1.5 \mathrm{kOe}$ to about $3 \mathrm{kOe}$ as $T_{\mathrm{s}}$ is increased from 300 to $775 \mathrm{~K}$. These values at $6 \mathrm{~K}$ are essentially those of the ground state. The values of $H_{c}$ at $300 \mathrm{~K}$ are considerably reduced as expected, but the reductions are not proportional to the values at $6 \mathrm{~K}$. This is because the temperature dependence of $Z_{c}$ is largely dictated by the granule size; the more pronounced temperature dependence ocurring in the smaller granules. Consequenty, for the smaller granules $\left\{T_{s}\right.$ $<475 \mathrm{~K}, H_{c}$ is essentially zero at $300 \mathrm{~K}$. On the other hand, for samples with $T_{s}>800 \mathrm{~K}, H_{c}$ at both 6 and $300 \mathrm{~K}$ also decreases precipitously. There are two likely causes. The granule sizes for these samples are about $150 \AA$, approaching the estimated critical size of $200 \AA$ for single-domain Fe particles. Some granules may become multidomain, which drasrically degrades $H_{c}$. A more likely cause, however, is the alteration of the granular structure at high temperatures. The TEM micrograph shown in Fig. $2(b)$ indicates sintering between the granules. The partially connected granules effectively allow the formation of multiomain, thus reducing $H_{c}$.

A maximum of $H_{c}$ at both 6 and $300 \mathrm{~K}$ is achieved with
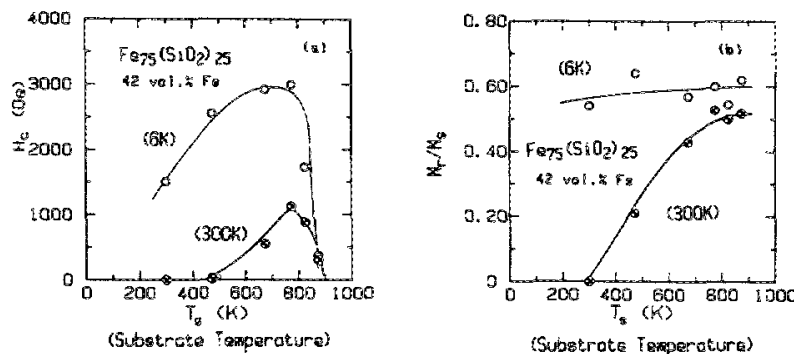

FIG. 4. Variations of (a) coercivity and (b) squareness of $\mathrm{Fe}_{75}\left(\mathrm{SiO}_{2}\right)_{25}$, $p=0.42$, at 6 and $300 \mathrm{~K}$ as a function of substrate temperarures. 
$T_{s}=775 \mathrm{~K}$. The values of $H_{c}$ of $3 \mathrm{kOe}$ (at $6 \mathrm{~K}$ ) and $1.1 \mathrm{kOe}$ (at $300 \mathrm{~K}$ ) are among the highest for Fe particles. The high value at $300 \mathrm{~K}$ is particularly encouraging for possible recording media applications.

In Fig. 4(b) we show the squareness, defined as the ratio of remanence and saturation magnetization. The squareness at $6 \mathrm{~K}$ is about 0.6 , essentially independent of $T_{s}$. As expected, the squareness at $300 \mathrm{~K}$ is reduced, but the reduction is much more for the smaller particles for the same reasons mentioned earlier. The squareness at $300 \mathrm{~K}$ is also the highest for $T_{s}>775 \mathrm{~K}$, as in the case of $H_{c}$.

Finally, we should mention some possible causes for the giant coercivity. It is well known that for single-cionain equiaxial Fe particles, $H_{c}$ is of the order of $2 K / M$, where $K$ includes all contributions (magnetocrystalline, stress, surface, etc.) to the magnetic anisotropy. Since magnetization $(M)$ is essentially independent of particle size, a larger $H_{c}$ would necessarily mean $K$ scales with the particle size in the present case. If one makes the overly simplistic assumption that magnetocrystalline anisotropy is the only contribution and that its magnitude is the same as that of bulk Fe, one concludes that $H_{c}$ should be only about $6000 \mathrm{O}$ and independent of particle size. ${ }^{6,7}$ It is clear then that some contributions, particularly those due to surface and stress, may well acquire much enhanced values, because the Fe granules are not free standing, but bonded in the $\mathrm{SiO}_{2}$ matrix. Other pos- sible causes for the enhanced $H_{c}$ are particles with large aspect ratio or particles forming very long chains. Neither of these possibilities are revealed in TEM micrographs, although there are evidences of neighboring granules in contact.

In summary, by exploiting granular $\mathrm{Fe}-\mathrm{SiO}_{2}$ solids with large granular sizes (about $150 \AA$ ), we have achieved roomtemperature coercivity of $1.1 \mathrm{kOe}$ and magnetization of 150 emu/g. These materials may be produced by sputtering with the use of suitable process conditions, of which substrate temperature is the most important. These superior magnetic characteristics compare favorably with those of existing magnetic recording media. The deposition methods, with which granular magnetic solids are made, are particularly suitable for magnetic thin-film applications.

This work was supported by the Office of Naval Research, contract No. No001485-K-0175.

${ }^{1}$ See, e.g., M. H. Kryder and A. B. Bortz, Phys. Today 37, 20 (1984).

${ }^{2}$ B. Abeles, P. Sheng, M. D. Couts, and Y. Arie, Adv. Phys. 24, 407 (1975).

${ }^{3}$ Gang Xiao and C. E. Chier, Appl. Phys. Lett. 51, 1280 (1987).

${ }^{4}$ W. T. Maloney, IEEE Trans. Magn. MAG-17, 3196 (1981).

${ }^{5} \mathrm{G}$. Bate, J. Appl. Phys. 52, 2447 (1981).

'See, e.g., A. H. Morrish, The Physical Principles of Magnetism (Wiley, New York, 1965).

${ }^{7}$ I. S. Jacobs and C. P. Bean, in Magnetism $I I T$, edied by G. T. Rado and H. Suhl (Academic, New York, 1963), p. 275. 